\title{
State-dependent modulation of stimulus- response relations in cortical networks in vitro
}

\author{
Oliver Weihberger ${ }^{1,2,3^{*}}$, Ayal Lavi ${ }^{4}$, Samora Okujeni ${ }^{1,2,3}$, Uri Ashery ${ }^{4}$, Ulrich Egert ${ }^{1,3}$ \\ From Twentieth Annual Computational Neuroscience Meeting: CNS*2011 \\ Stockholm, Sweden. 23-28 July 2011
}

Variable responses of neuronal networks to repeated identical electrical or sensory stimuli reflect the interaction of the stimulus' response with ongoing activity and its modulation by adaptive mechanisms such as cognitive context, network state, cellular excitability or synaptic transmission capability. To identify the rules that underlie the modulation of stimulus-response relations we set up a state-dependent stimulation paradigm in generic neuronal networks in vitro.

Extracellular neuronal activity was recorded and stimulated from rat cortical cell cultures on microelectrode arrays at 60 sites. Spontaneous and evoked network activity was examined under control conditions, under blockage of $\mathrm{GABA}_{\mathrm{A}}$-receptors as well as under overexpression of the synaptic protein DOC2B [1]. We were interested in the interactions that arise between spontaneous and stimulus-evoked activity dynamics and how these shape and modulate stimulus-response relations.

Spontaneous network activity consisted of recurring periods of globally synchronized burst firing, so-called network bursts. The duration of intervals that preceded network bursts best predicted the length of the following network burst. This supported a process of network depression to a low threshold during bursts followed by subsequent recovery [2]. Facilitation of synaptic transmission by overexpressing DOC2B yielded $\sim 30 \%$ more spikes per network burst. The intervals between bursts increased by $\sim 75 \%$, suggesting interdependence between resource activation and the time it needs for them to be recovered.

Response length and delay depended on the timing of stimulation relative to preceding bursting. Response length increased exponentially and saturated with increasing duration of pre-stimulus inactivity $t, y(t)=A$

\footnotetext{
* Correspondence: weihberger@bcf.uni-freiburg.de

${ }^{1}$ Bernstein Center Freiburg, University of Freiburg, Freiburg, 79104, Germany

Full list of author information is available at the end of the article
}

$\left(1-\mathrm{e}^{-\alpha \mathrm{t}}\right)$. Response delay, in turn, decreased exponentially and saturated at a low level, $y(t)=\mathrm{Be}^{-\beta \mathrm{t}}+\mathrm{C}$. The rate constant $\beta$ describes the coupling between recovery from depression and response delay. We found activitydependent recovery dynamics with longer spontaneous bursts yielding smaller $\beta$ and vice versa.

Stimulus-response modulation persisted under the blockage of inhibition, that introduced overall longer responses and shorter delays. Longer network bursts with more spikes occurred less frequently and recovery rates concomitantly decreased. The average firing rate was, however, unchanged, supporting a pool of available resources that is repeatedly used and replenished during and between network bursts, respectively.

\section{Conclusion}

The timing of stimulation relative to spontaneous bursting modulates stimulus-response relations in cortical networks in vitro following distinct rules. The interrelation between resource depletion and replenishment determines the temporal evolution of the network's excitability state. Our findings can be explained by short-term synaptic depression and activity-dependent adaptation of excitability as underlying mechanisms.

\section{Acknowledgements \\ This work was supported by the German BMBF (FKZ 01GQ0420 \& FKZ 01GQ0830) and the Boehringer Ingelheim Fonds.}

\section{Author details}

${ }^{1}$ Bernstein Center Freiburg, University of Freiburg, Freiburg, 79104, Germany. ${ }^{2}$ Faculty of Biology, Neurobiology and Biophysics, University of Freiburg, 79104 Freiburg, Germany. ${ }^{3}$ IMTEK - Dept. of Microsystems Engineering, University of Freiburg, Freiburg, 79110, Germany. ${ }^{4}$ Deptartment of Neurobiology, Tel Aviv University, Tel Aviv, 69978, Israel.

Published: 18 July 2011 


\section{References}

1. Friedrich $\mathrm{R}$, Groffen $\mathrm{AJ}$, Connell $\mathrm{E}$, van Weering JR, Gutman $\mathrm{O}$, Henis $\mathrm{YI}$, Davletov B, Ashery U: DOC2B acts as a calcium switch and enhances vesicle fusion. J Neurosci 2008, 28(27):6794-806.

2. Tabak J, Rinzel J, O'Donovan MJ: The role of activity-dependent network depression in the expression and self-regulation of spontaneous activity in the developing spinal cord. J Neurosci 2001, 21(22):8966-78.

doi:10.1186/1471-2202-12-S1-06

Cite this article as: Weihberger et al:: State-dependent modulation of stimulus-response relations in cortical networks in vitro. $B M C$

Neuroscience 2011 12(Suppl 1):O6

Submit your next manuscript to BioMed Central and take full advantage of:

- Convenient online submission

- Thorough peer review

- No space constraints or color figure charges

- Immediate publication on acceptance

- Inclusion in PubMed, CAS, Scopus and Google Scholar

- Research which is freely available for redistribution

Submit your manuscript at www.biomedcentral.com/submit
Ciomed Central 